\title{
O NASCIMENTO DO ALTO: O ESPÍRITO SANTO NA TEOLOGIA JOANINA EM UMA ANÁLISE A PARTIR DE JOÃO 3.1-6
}

\section{The birth of the high: the holy spirit in john theology in an analysis from John 3.1-6}

\author{
Amós Silva Jubim* \\ Magno Lessa do Espírito Santo** \\ Paulo Jonas dos Santos Júnior**
}

\section{Resumo:}

O presente artigo investiga o diálogo entre Jesus e Nicodemos, narrado em João 3.1-6. Para tanto, parte da seguinte pergunta: qual o papel do Espírito Santo no novo nascimento a partir de João 3.16? Para o autor, há duas realidades que estão em constate contraste: luz e trevas, morte e vida, noite e dia, mundo de cima e mundo de baixo. Nessa perícope, este contraste aparece: mundo de cima (do Espírito) e o de baixo (da carne). Assim sendo, quem nasce de baixo, nasce da carne, mas quem nasce do alto, nasce do Espírito. Para participar do Reino escatológico de Deus, Nicodemos tem de nascer de novo/do alto, isto é, do Espírito. Logo, na teologia joanina, a participação no Reino de Deus não se dá pelas obras da Lei, mas pela ação do Espírito no mundo.

Palavras-chave: Dualismo Joanino; Nascimento do Alto; Reino de Deus; Espírito Santo.

\section{Abstract:}

The present article investigates the dialogue between Jesus and Nicodemus, narrated in John 3.1-6. Therefore, it starts from the following question: what is the role of the Holy Spirit in the new birth from John 3.1-6? For the author, there are two realities that are in constant contrast: light and darkness, death and life, night and day, world above and world below. In this pericope, this contrast appears: the world above (of the Spirit) and the world below (of the flesh). So whoever is born from below is born of the flesh, but whoever is born from above is born of the Spirit. To participate in the eschatological Kingdom of God, Nicodemus must be born again / from above, that is, from the Spirit. Therefore, in Johannine theology, participation in the Kingdom of God does not occur through the works of the Law, but through the action of the Spirit in the world.

1 Enviado em: 09.01.2019. Aceito em: 12.06.2020.

* Pós-Graduando em Docência no Ensino Superior. Graduado em Psicologia pelo Centro Universitário São José de Itaperuna (UNIFSJ). Graduando em Teologia pelo Centro Universitário São José de Itaperuna (UNIFSJ). E-mail: amosjubim@gmail.com

** Mestre em Ciências das Religiões pela Faculdade Unida de Vitória (FUV). Especialista em Teologia Bíblica do Novo Testamento Aplicada pela Faculdade Batista do Paraná (FABAPAR). Bacharel em Teologia pela Universidade Presbiteriana Mackenzie (UPM) e pelo Instituto Bíblico das Assembleias de Deus (IBAD). Licenciado em Filosofia pelo Instituto de Ciências Sociais e Humanas (ICSH). Docente do Centro Universitário São José de Itaperuna (UNIFSJ). Email: magno lessa@hotmail.com

** Doutorando em Planejamento Regional e Gestão da Cidade pela Universidade Cândido Mendes (UCAM). Mestre em Ciências das Religiões pela Faculdade Unida de Vitória (FUV). Especialista em História e Cultura do Brasil pela Universidade Estácio de Sá (UNESA). Licenciado em História (ISEIB). Bacharel em Teologia (FAECAD). Psicanalista Clínico (FATEB). Docente do Centro Universitário São José de Itaperuna. E-mail: paulojsjunior@hotmail.com

Protestantismo em Revista | São Leopoldo | v. 45, n. 02 | p. 167-176| Jul./dez. 2019

Disponível em: <http://periodicos.est.edu.br/index.php/nepp> 
Keywords: Joanine Dualism; Birth from Above; God's kingdom; Holy Spirit.

\section{Introdução}

O Evangelho de João, devido a algumas peculiaridades, se diferencia dos sinóticos. No texto, o autor desenvolve o conceito dualístico, ou seja, de duas realidades que estão em constante contraste: luz e trevas, morte e vida, mundo de cima e mundo de baixo. É à luz desses dualismos que o Evangelho de João, ao apresentar o diálogo de Jesus com Nicodemos, afirma a necessidade de nascer do alto (do Espírito) em contraste com o nascer de baixo (da carne). Logo, tendo esse aspecto da teologia joanina em tela, o presente artigo procura investigar a seguinte questãoproblema: qual o papel do Espírito Santo no novo nascimento, partindo de João 3.1-6?

Para tanto, faz-se necessário apresentar o dualismo joanino, visto que o contraste entre os dois mundos aparece na perícope em análise. Feito isso, investigaremos o conceito de novo nascimento - uma definição do termo -, para só então apontar a finalidade do Espírito Santo e sua participação no nascer de novo/do alto. A escolha do tema deve-se à observação empírica de que há necessidade de um aprofundamento teórico no papel do Espírito Santo no contexto joanino.

Assim, a presente pesquisa não tem por objetivo esgotar o assunto, mas se pretende ser uma proposta interpretativa para o texto, contribuindo como um aporte teórico e visando a um progresso no que diz respeito à maneira como se compreende o novo nascimento e o papel do Espírito Santo na narrativa do Evangelho de João, apresentando, enfim, relevância social e acadêmica.

\section{O contexto histórico do Evangelho de João}

A princípio, cumpre salientar que boa parte da diferença entre João e os sinóticos se dá por conta de seu background, isto é, as circunstâncias em que foi escrito. Enquanto os sinóticos enfatizam a atividade de Jesus na Galileia e nas regiões circunvizinhas com uma única viagem a Jerusalém e, consequentemente, a crucificação, em João, Jesus vai três vezes da Galileia a Jerusalém (2.13-5.1; 7.1). Outra diferença pode ser vista na descrição e ensinamento de Jesus, pois em João, o ensinamento de Jesus é composto de diferentes descrições ${ }^{2}$ e depoimentos isolados ou "grupos de depoimentos, os quais são reunidos para formar uma série de descrições e raciocínios". ${ }^{3}$

Além disso, não só quanto à estrutura João se diferencia dos sinóticos, mas também quanto ao material utilizado. São poucas as narrativas em semelhança com os sinóticos: a vocação dos discípulos (Jo 1.35ss), a cura do filho do funcionário real (Jo 4.46ss), a multiplicação dos pães e peixes (Jo 6.1), a confissão de Pedro (Jo 6.66ss), a entrada na cidade de Jerusalém (Jo 12.12ss) e a última ceia (Jo 13.1ss). Segundo Kümmel, a narrativa da purificação do templo (Jo 2.13ss) e a unção de Betânia (Jo 12.1ss), encontram correspondência ${ }^{4}$ nos sinóticos, mas em contextos diferentes. Por

2 O evangelho de João é constituído de grandes composições justapostas em forma de discurso e, parcialmente, dialógicas, sendo que também nele somente a história da paixão constitui um relato contínuo. Cf. KÜMMEL. Síntese Teológica do Novo Testamento. São Paulo: Teológica, 2003, p. 319.

3 KÜMMEL, Werner Georg. Introdução ao Novo Testamento. 17 ed. São Paulo: Paulus, 1982, p. 254.

4 Em vários pontos, João tem ligação com tradições presentes em Marcos, Lucas e, em grau menor, Mateus. Alguns pesquisadores sustentam que João dependeu de um ou mais sinóticos, mas, comumente de Marcos. Outros

Protestantismo em Revista | São Leopoldo | v. 45, n. 02 | p. 167-176| Jul./dez. 2019

Disponível em: <http://periodicos.est.edu.br/index.php/nepp> 
fim, o Evangelho de João pressupõe fatos narrados nos sinóticos, todavia sem mencioná-los: a atividade batismal de João Batista (Jo 1.26), o batismo de Jesus (Jo 1.32), a prisão de João Batista (Jo 3.24) e a cena ocorrida no Getsêmani (Jo 12.27). ${ }^{5}$

Nota-se uma herança judaica no evangelho de João; não obstante uma menor citação do Antigo Testamento (apenas quatorze vezes), há temas veterotestamentários que podem ser encontrados nesse evangelho, como o Bom Pastor e a Videira Verdadeira, por exemplo. Cabe ressaltar que, durante a época de Jesus e a formação dos Evangelhos, o judaísmo rabínico se centralizava em torno da sinagoga e os fariseus "[...] nutriam o estudo escrito do Antigo Testamento e a tradição oral que os cercava [...]." 6 Por esta razão, cumpre observar que, em João, boa parte do ministério de Jesus se passa em Jerusalém, onde se localizava o centro religioso, e a maioria das controvérsias de Jesus era com membros do Sinédrio, tais como Nicodemos.

A influência helênica sobre o quarto evangelho se dá por um motivo específico: o cristianismo - religião de base judaica - precisava ser interpretado e apresentado a uma cultura estrangeira. Nesse intuito, João adota um termo utilizado por Filo de Alexandria, um judeu imbuído da tarefa de apresentar o judaísmo à Filosofia Grega. Filo utilizou o termo grego logos com a comunidade judaica e no prólogo do evangelho o autor apresenta Jesus como o Verbo (logos) encarnado. ${ }^{7}$

É importante destacar que o significado desse termo (logos) é debatido. Conforme Blomberg, a expressão é bastante usada em ampla variedade nas fontes helenísticas e judaicas. 0 panteísmo estoico se referia ao logos como a força responsável por animar a vida ou a "alma do mundo". Nos targuns, ele substituiu o nome de Deus, especialmente em Gênesis 1 . Assim, o que se tem é que o termo era usado para se referir ao modo como Deus ou os deuses se revelavam à humanidade. Logo, de acordo com Blomberg, o evangelho de João "pode muito bem estar explorando tal contexto diversificado para enfatizar que Jesus é a forma pela qual o Deus vivo e verdadeiro se revela e se comunica com seu povo". ${ }^{8}$

Após o prólogo (João $1.1-1.18$ ), o autor ${ }^{9}$ estrutura o texto de modo a apresentar o que Hale e, na mesma linha, Köstenberger e Swain chamam de "livro dos sinais"10 (Jo 1.19 - 12.50). 0 evangelho apresenta Jesus realizando sete "sinais", milagres que confirmam sua missão: 1) Bodas de Caná (2.1-11); 2) cura do filho de um funcionário real (4.46-54); 3) cura de um enfermo na piscina de Betesda (5.1-18); 4) multiplicação dos pães (6.1-15); 5) Jesus anda sobre o mar (6.16-21); 6) cura de um cego de nascença (9.1-41); 7) ressurreição de Lázaro (11,1-44). Nas palavras de Mincato:

sugerem que o impulso para colocar as tradições joaninas sobre Jesus na forma de um evangelho resultou da aparição de evangelhos em outras comunidades, que o evangelista pode ter tido algum conhecimento de um ou mais dos sinóticos, mas que o Quarto Evangelho se baseia em uma linha independente de tradição preservada nas igrejas joaninas. Cf. PERKINS, Pheme. Evangelho segundo João. In BROWN, Raymond E. FITZMYER, Joseph A. MURPHY, Roland E. Novo comentário Bíblico São Jerônimo: Novo Testamento e artigos sistemáticos. Tradução de Celso Eronides Fernandes. Santo André (SP): Academia Cristã; São Paulo: Paulus, 2011, p. 732.

5 KÜMMEL, 1982, p. 254.

6 HALE, B. D. Introdução ao Estudo do Novo Testamento. São Paulo: Hagnos, 2001, p. 157.

7 HALE, 2001, p. 159.

8 BLOMBERG, Craig L. Jesus e os evangelhos: uma introdução ao estudo dos 4 evangelhos. São Paulo: Vida Nova, 2009, p. 215.

9 Não há concordância sobre a autoria do texto, para Brown o texto é fruto da comunidade joanina. Cf. BROWN, R. E. A Comunidade do Discípulo Amado. São Paulo: Paulus, 1999.

10 KÖSTENBERGER, Andreas J. SWAIN, Scott R. Pai, Filho e Espírito: a trindade e o evangelho de João. São Paulo: Vida Nova, 2014, p. 65-72.

Protestantismo em Revista | São Leopoldo | v. 45, n. 02 | p. 167-176| Jul./dez. 2019

Disponível em: <http://periodicos.est.edu.br/index.php/nepp> 
O "Livro dos Sinais", do ponto de vista narrativo, relata os sete sinais realizados por Jesus ao longo do ministério público, começando exatamente nas Bodas de Caná. Jesus já é conhecido pelos seus discípulos e apresenta-se em plena atividade adulta, deslocando-se continuamente entre a Galileia e Jerusalém. Os sete sinais, gestos (expulsão dos vendilhões do Templo), diálogos (com Nicodemos, com a Samaritana, com Marta e Maria), o discurso revelatório aos discípulos (Jo 6), as controvérsias com os Judeus (Jo 5, 7, 8, 10) ao longo deste livro querem conduzir o leitor para a realidade da fé naquele que realiza os Sinais e que revela a sua "glória" por meio deles: a glória, que se revelará definitivamente na "hora" da elevação na cruz. ${ }^{11}$

A segunda unidade do livro (11.1 - 20.29), é o "livro da hora, da conclusão e da volta ao Pai". "Antes da festa da Páscoa, sabendo Jesus que chegara a sua hora de passar deste mundo para o Pai, tendo amado os seus que estavam no mundo, amou-os até o fim."12 O livro da hora está delimitado pelo início do sétimo sinal e pela conclusão (20.30-31).${ }^{13}$ Feita a apresentação da estrutura desse Evangelho, podemos nos deter na perícope em tela.

O primeiro sinal apresentado é a transformação da água em vinho em Caná da Galileia. É neste contexto, como testemunho do primeiro sinal, que segue a perícope em análise. Nos seis primeiros versículos do capítulo 3, dois personagens são apresentados: um farise ${ }^{14}$, a quem o autor apresenta como Nicodemos, e Jesus. Na narrativa da cena, Nicodemos se aproxima de Jesus durante a noite e eles iniciam um diálogo que gira em torno do novo nascimento. No diálogo, Nicodemos é apresentado como archōn tōn loydaiōn (líder dos judeus). Para Bruce, ele era membro dos fariseus no sinédrio. ${ }^{15}$ Além disso, Nicodemos tem sido identificado com Naqdimon ben Gorion, um cidadão rico de Jerusalém, porém Carson vê problemas com essa identificação:

O nome Nicodemos era comum em grego, mas transliterado e transformado em um nome judeu. Identifica-se esse Nicodemos, algumas vezes, com Naqdimon ben Gorion, um cidadão rico de Jerusalém que supria os peregrinos com água nas principais festas, e que, conforme se sabe, viveu em Jerusalém no tempo de seu cerco na guerra judaica [...]. Isso faria com que Naqdimon fosse um homem muito jovem quarenta anos antes, durante o ministério de Jesus, provavelmente muito jovem para ter sido uma autoridade entre os judeus, um membro do Sinédrio, a menos que fosse de fato uma pessoa muito excepcional. ${ }^{16}$

Parece-se nos que, à luz do versículo 4, Nicodemos era já um homem de idade avançada quando encontrou Jesus. Por mais que seja difícil determinar quem ele era, tomemos a maneira como o texto o apresenta: líder dos judeus. Em tal posição de prestígio, certamente era um homem culto; porém, em diálogo com Jesus, Nicodemos tem dificuldade de entender o que o Mestre deseja expressar com "nascer do alto; da água e do Espirito" e é nesse ponto que a discussão se dá, uma

11 MICANTO, Ramiro. A macroestrutura narrativa do quarto evangelho. In: Revista Teocomunicação. Porto Alegre, v.37, n. 155,2007, p. 49-49; 52-53.

12 BIBLIA, Bíblia de Jerusalém. São Paulo, Paulus, 2002.

13 MICANTO, 2007, p. 53.

14 Nicodemos pertencia ao partido dos fariseus. Esse partido parece ter-se originado durante o período que precedeu as guerras macabéias. "Sua origem pode também ser entendida como a cristalização de uma reação contra o espírito secularizado do helenismo." Durante o século $2^{\circ}$ antes de Cristo, as pessoas que abom inavam os costumes idólatras dos gregos, e que, durante a terrível perseguição religiosa liderada pelo monstruoso Antíoco Epifânio, tinham permanecido firmes, recusando-se a abandonar a fé, foram chamadas hasidins (piedosos ou santos). Eles foram os precursores dos fariseus (separatistas), que começaram a usar esse nome durante o reinado de João Hircano (135105 a.C.). Cf. HENDRIKSEN, Willian. O Evangelho de João. São Paulo: Cultura Cristã, 2004, p. 178.

15 BRUCE, F. F. João: introdução e comentário. São Paulo: Vida Nova, 1987, p. 79.

16 CARSON, D. A. Comentário de João. São Paulo: Shedd Publicações, 2007, p. 186.

Protestantismo em Revista | São Leopoldo | v. 45, n. 02 | p. 167-176| Jul./dez. 2019

Disponível em: <http://periodicos.est.edu.br/index.php/nepp> 
vez que Jesus aproveita o diálogo com Nicodemos para introduzir um assunto que o autor do evangelho faz questão de abordar: o novo nascimento ou o nascimento do alto.

\section{0 dualismo em João}

Para melhor compreensão da perícope em apreço (João 3.1-12), é importante salientar que, no Evangelho de João, o autor usa uma característica muito marcante: o dualismo. O dualismo não aparece unicamente em João, mas pode ser encontrado também nos sinóticos, porém com grandes diferenças. O dualismo nos sinóticos é apresentado de modo horizontal, ou seja, o contraste se dá entre duas eras: a era presente e a era futura. Segundo Ladd, "os sinóticos contrastam esta era com o século futuro, e sabemos por intermédio do uso paulino que 'este mundo' pode ser equivalente à expressão 'esta era' em um dualismo escatológico."17 Dessa maneira, pode-se inferir que o dualismo utilizado nos sinóticos propõe uma ideia escatológica.

O dualismo joanino, por sua vez, não é apresentado de modo horizontal - diferente dos sinóticos -, mas de modo vertical. João não propõe um contraste escatológico entre esta era e a vindoura, mas sua ideia contrapõe dois mundos: o de baixo e o de cima. A partir do dualismo entre os dois mundos (o de baixo e o de cima), tem-se o desdobramento dos demais dualismos. Podemos citar, por exemplo: trevas e luz, carne e Espírito, velho e novo, morte e vida, noite e dia, dentre outros. ${ }^{18}$ Para Carson, a expressão "noite", por exemplo, apresentada na estrutura narrativa de João 3.1-6, apresenta um duplo entendimento, ou seja, um literal e o outro metafórico. Vejamos o que ele diz:

A melhor pista encontra-se no uso de "noite", por João, em outra passagem: em cada instância $(3.2 ; 9.4 ; 11.10 ; 13.30)$ utiliza-se a palavra ou metaforicamente para escuridão moral e espiritual. Sem dúvida, Nicodemos se aproximou de Jesus à noite, mas sua própria "noite" era mais escura do que ele pensava. ${ }^{19}$

Cabe assinalar que, nos contrastes traçados por João, as associações devem ser feitas da seguinte maneira: o mundo de baixo é governado pelo diabo (16.11), o qual está associado às trevas e ao nascimento pela carne; e o mundo de cima, vinculado à luz (que, para o autor, é o próprio Jesus) e ao nascer do alto, pelo Espírito. Assim sendo, poderíamos listar aqui todos os momentos em que essa estrutura dualista aparece no Evangelho de João, mas isso fugiria do propósito da presente pesquisa. Entretanto acreditamos que o exemplo acima serve como um bom indicativo de que as imagens com traços dualísticos em João devem ser avaliadas com cuidado, pois em determinados momentos podem ser apenas metáforas, em outros serem literais, ou ainda, como acontece na perícope em análise, conter o sentido literal e o metafórico ao mesmo tempo.

17 LADD, George Eldon. Teologia do Novo Testamento. São Paulo: Hagnos, 2003, p. 338.

18 LADD, 2003, p. 338.

19 CARSON, 2007, p. 187.

Protestantismo em Revista | São Leopoldo | v. 45, n. 02 | p. 167-176| Jul./dez. 2019

Disponível em: <http://periodicos.est.edu.br/index.php/nepp> 


\title{
O Novo Nascimento em João
}

Dentre os desdobramentos que se pode visualizar em relação aos dois mundos, encontrase o nascer da carne e o nascer do alto/de novo. O diálogo de Nicodemos e Jesus se desenvolve em torno deste contraste, como se lê na perícope de João 3.1-6:

\begin{abstract}
Havia, entre os fariseus, um homem chamado Nicodemos, um notável entre os judeus. À noite ele veio encontrar Jesus e lhe disse: "Rabi, sabemos que vens da parte de Deus como mestre, pois ninguém pode fazer os sinais que fazes, se Deus não estiver com ele". Jesus Ihe respondeu: "Em verdade, em verdade, te digo: quem não nascer de novo não pode ver o Reino de Deus". Disse-Ihe Nicodemos: "Como pode um homem nascer, sendo já velho? Poderá entrar segunda vez no sei de sua mãe e nascer?" Respondeu-lhe Jesus: Em verdade, em verdade, te digo: quem não nascer da água e o Espírito não pode entrar no Reino de Deus. O que é nascido da carne é carne, o que é nascido do Espírito é espírito. ${ }^{20}$
\end{abstract}

Um importante detalhe no início do diálogo é que o autor mostra que Nicodemos começou a tentar compreender o propósito do Evangelho, quando o fariseu diz a Jesus: "Rabi, sabemos que vens da parte de Deus como mestre, pois ninguém pode fazer os sinais que fazes, se Deus não estiver com ele" (Jo 3.2). ${ }^{21}$ Nicodemos percebe que Jesus é "vindo de Deus", isto é, pertence ao mundo de cima e opera sinais [o que estrutura o Evangelho de João]. Nas palavras de Carson:

\begin{abstract}
É a evidência dos sinais miraculosos que convence Nicodemos de que Jesus não é um mestre comum: ele deve ser um mestre vindo de Deus - o que certamente não é uma confissão da preexistência de Jesus, mas um reconhecimento de que Deus estava peculiarmente com ele, da mesma forma que estava com Moisés ou Jeremias [...] Nicodemos não sugere que Jesus seja um profeta, muito menos o profeta ou o Messias, mas simplesmente um mestre poderosamente cotado com o poder de Deus. Nicodemos estava claramente curioso sobre Jesus, mas ainda ficou muito longe de uma confissão de que ele fosse exclusivamente o prometido [...]. ${ }^{22}$
\end{abstract}

É imprescindível compreender que, formalmente, Nicodemos não havia perguntado nada, no entanto, em sua afirmação, pode-se perceber implícita uma curiosidade de saber quem é Jesus. A partir dessa afirmativa de Nicodemos, Jesus propõe que o novo nascimento/nascimento do alto, que equivale ao nascimento da água e do Espírito, é condição básica para ver/entrar no Reino de Deus.

O Reino de Deus é uma expressão que (completa) não ocorre no Antigo Testamento. Não obstante, uma rica quantidade de passagens aborda o reinado do Senhor e insiste que o Senhor reina, isto é, é Rei. Ademais, "[...] os profetas previram o advento de um reino no fim da história [...]"23 numa perspectiva messiânica, um reino vindouro. Logo, para um judeu como Nicodemos, ver o Reino de Deus era experimentar a vida eterna no sentido utilizado pelos sinóticos. Uma observação a ser feita é que nos dias de Jesus o pensamento religioso predominante postulava que "[...] todos os judeus seriam admitidos naquele Reino, exceto os culpados de deliberada apostasia ou extraordinária impiedade". Sendo mestre dos judeus e integrante do Sinédrio, com base no pensamento religioso vigente da época, era impossível que Nicodemos ficasse de fora, todavia Jesus mostra a ele que sua entrada no Reino de Deus não seria garantida a menos que nascesse "de

20 BIBLIA, Bíblia de Jerusalém. São Paulo, Paulus, 2002.

21 BIBLIA, Bíblia de Jerusalém. São Paulo, Paulus, 2002.

22 CARSON, 2007, p. 187.

23 CARSON, 2007, p. 188.

Protestantismo em Revista | São Leopoldo | v. 45, n. 02 | p. 167-176| Jul./dez. 2019

Disponível em: <http://periodicos.est.edu.br/index.php/nepp> 
novo." ${ }^{24}$ Assim, de acordo com Marshall, o engano de Nicodemos é usado por Jesus para se entender a natureza do novo nascimento. ${ }^{25} \mathrm{O}$ termo grego para nascer de novo/do alto é anothen, ${ }^{26}$ que "pode significar 'do alto' ou 'de novo'. Como Nicodemos entendeu que ele significava 'de novo' e Jesus não o corrigiu, alguns estudiosos afirmam que 'de novo' 27 pode ser mantido" 28 , embora caiba ressaltar que anothen, em João, pode significar "do alto." 29

Segundo Carson, o autor pode ter escolhido estender o duplo significado para essa expressão. Nascer de novo/do alto, pode ser então compreendido no mesmo sentido "[...] que 'se tornar filho de Deus', 'nascer de Deus', por meio da fé no nome da Palavra encarnada" ${ }^{30}$, como se lê em João 1.12-13. Portanto, nascer de novo/do alto significa, no contexto joanino, tonar-se filho de Deus pela fé em Jesus. Keener salienta que "alto", neste texto, é o lugar de Deus no entendimento do dualismo vertical joanino, além de ter se tornado uma circunlocução para Deus em vários meios judaicos. ${ }^{31}$

Diversas tentativas de traçar a origem do termo "nascer de novo/do alto" foram feitas. Há comentadores que conectam o termo a ramos do gnosticismo e paganismo; outros apelam para fontes judaicas, compreendendo como o banho dos prosélitos, no qual o batizado é tido como uma criança recém-nascida; há ainda quem ventile que a perícope em apreço se trata da versão joanina de Mt 18.3 que destina o Reino dos Céus àqueles que se tornam criancinhas. Todavia, o foco do texto não enfatiza apenas uma purificação ou quebrantamento e humildade, no caso de considerarmos as interpretações supracitadas. ${ }^{32}$ Para Keener, no entanto, nascer da água em João 3.5 pode se referir à prática do batismo de prosélitos. Assim, ele indica que esse tipo de purificação, de acordo com o contexto, seria para os judeus religiosos, como no caso de Nicodemos, e para os gentios. ${ }^{33}$

Nessa perspectiva, até um homem como Nicodemos, com sua piedade e religiosidade, precisa de uma transformação radical, da geração de uma nova vida, que se possa comparar ao nascimento físico. ${ }^{34}$ É, portanto, nesse sentido que a expressão é utilizada: para indicar a necessidade de uma nova vida, que vem do alto e credencia o ser humano para o acesso ao Reino de Deus.

24 CARSON, 2007, p. 189.

25 MARSHALL, I. Howard. Teologia do Novo Testamento: diversos testemunhos, um só evangelho. São Paulo: Vida Nova, 2007, p. 431.

26 Extensão a partir de uma fonte que está acima - "de cima, do alto, do topo de". O termo é usado algumas vezes no Novo Testamento com o sentido de "de cima" (Jo 19.11; Mc 15.38; Jo 19.23; Jo 3.31. Cf. LOUW, Johannes. NIDA, Eugene. Léxico Grego-Português do Novo Testamento baseado em domínios semânticos. Sociedade Bíblica do Brasil, 2013, p. 642).

27 A expressão também é usada com o sentido de "de novo". Em Jo 3, nascer de novo, isto é, passar por uma completa mudança no modo de vida, fazendo com que seja o que deveria ser, com a implicação de que se trata do retorno a um estado ou um relacionamento anterior (LOUW; NIDA, 2013, p. 454).

28 CARSON, 2007, p. 189.

29 O fato de esses termos aparecerem nos textos de muitos autores cristãos primitivos, Tiago (1,18,21), 1Pedro (1.23; 2.2) e na tradição de Jesus ( $M t$ 18.3, Mc 9.37; Lc 9.48) também é um forte indício da antiguidade desse conceito. Cf. KEENER, Craig S. O Espírito nos evangelhos e em Atos: pureza e poder divino. São Paulo: Vida Nova, 2018, p. 209.

30 CARSON, 2007, p. 190.

31 KEENER, 2018, p. 209.

32 CARSON, 2007, p. 192-195.

33 KEENER, 2018, p. 215.

34 CARSON, 2007, p. 191.

Protestantismo em Revista | São Leopoldo | v. 45, n. 02 | p. 167-176| Jul./dez. 2019

Disponível em: <http://periodicos.est.edu.br/index.php/nepp> 


\section{A pneumatologia de João 3.1-6}

Vinculado ao nascer de novo/do alto, em resposta ao questionamento de Nicodemos, Jesus utiliza outra expressão: nascer da água e do Espírito. Cabe lembrar que, como padrão recorrente nesse evangelho, a resposta de Nicodemos é um mal-entendido seguido de mais explicações, ou seja, Nicodemos fica confuso, questionando sobre a possibilidade de um "homem velho" retornar para o ventre materno.

Esse mal-entendido, segundo Carson, pode ter duas explicações: ou Nicodemos entendeu que Jesus estava exigindo algum tipo de transformação e não via possibilidade de começar tudo como uma pessoa nova, ou numa visão mais realística, Nicodemos não entendeu nada do que Jesus estava falando e por isso não podia crer. ${ }^{35}$ Ambas as explicações tornam nítido que há um malentendido no diálogo, e Jesus oferece sua resposta numa tentativa de aclarar seu argumento para Nicodemos. Jesus, então, amplia o conceito de nascer de novo/do alto para nascer da água e do Espírito.

Há quem separe a expressão "água" de "Espírito", com fins interpretativos. Surgem, então, diversos entendimentos sobre o significado da água nesse contexto. Pode-se encontrar referências a água como o líquido amniótico que irrompe do útero logo antes do parto; ${ }^{36}$ há argumentos a favor de que a água se refira ao batismo cristão - o que seria um anacronismo; encontram-se interpretações que compreendam a água não como o batismo cristão, mas como o batismo de João Batista; há quem diga também que Jesus argumenta contra as lavagens rituais dos essênios e, por fim, é possível achar intérpretes que vejam a água nesse texto como símbolo da Torá. ${ }^{37}$

É importante dizer que se pode inferir de Carson que: (1) a interpretação de "nascer da água e do Espírito" precisa ser tomada como paralela da expressão "do alto"; (2) a forma mais natural de entender a frase não dissocia "água" de "Espírito", isto é, há uma fonte de água-espírito; (3) a censura de Jesus a Nicodemos acontece visto que este era "mestre de Israel", portanto o pano de fundo do Antigo Testamento é determinante na interpretação. Como Carson afirma:

nascer da água e do Espírito [...] assinala uma nova criação, um novo nascimento que purifica e renova, a purificação e renovação escatológicas prometidas pelos profetas do Antigo Testamento. É verdade que os profetas tendiam a focalizar os resultados coletivos e a restauração da nação; mas eles também antecipavam uma transformação dos 'corações' individuais - não mais corações de pedra, mas corações ansiosos por fazer a vontade de Deus. Parece que a regeneração individual está pressuposta. Aparentemente, Nicodemos não havia pensado nas passagens do Antigo Testamento dessa forma. Se ele era como outros fariseus, ele estava muito confiante da qualidade de sua própria obediência para pensar que necessitava de muito arrependimento [...] para não falar de ter toda sua vida purificada e seu coração transformado: nascer de novo (grifo do autor). ${ }^{38}$

Dessa forma, o nascer da água e do espírito pressupõe uma nova natureza, isto é, uma natureza do alto, gerada pelo Espírito. Segundo Ladd, a ideia é a de que o homem não possui vida (no sentido joanino), que essa vida é um dom de Deus "que somente pode ser efetivado por um trabalho interior do Espírito Santo, que faz do crente um filho de Deus". Ademais, para Ladd, a referência ao novo nascimento é semelhante ao entendimento paulino do "ser batizado em Cristo" e, dessa forma, "passa a viver em novidade de vida. A metáfora é diferente, mas a teologia é a

35 CARSON, 2007, p. 192.

36 CARSON, 2007, p. 192.

37 CARSON, 2007, p. 194.

38 CARSON, 2007, p. 196.

Protestantismo em Revista | São Leopoldo | v. 45, n. 02 | p. 167-176| Jul./dez. 2019

Disponível em: <http://periodicos.est.edu.br/index.php/nepp> 
mesma". ${ }^{39}$ A atuação do Espírito na vida do nascido do alto proporciona a este uma vida que não pode ser compreendida pelos que não experimentaram um novo nascimento (João 3.8). Carson traça um paralelo entre a perícope em apreço e o texto de Ezequiel 36-37, em que comenta:

[...] Como o nascimento da "água e espírito" é baseado em Ezequiel 36.25-27 [...], então pode haver uma alusão aqui a Ezequiel 37. Lá o sopro/Espírito de Deus [...] vem sobre o vale dos ossos secos e os ossos são revividos; o povo de Deus vem à vida. O mesmo acontece com todo aquele que é nascido do Espírito: ele tem sua 'origem e destino no Deus invisível' [...] não na decisão humana ou na vontade de um homem', porque eles são nascidos de Deus. ${ }^{40}$

Pode-se observar que as Escrituras, a que Nicodemos havia devotado anos de estudo, evidenciam o inegável poder do Espírito Santo. Percebe-se, então, que o papel do Espírito Santo, no contexto do novo nascimento, à luz da teologia joanina, é oferecer uma nova vida, baseada na natureza que vem do alto. Para Jürgen Moltmann, o Espírito Santo é a força da ressurreição dos mortos e da nova criação de todas as coisas; não é só uma questão de revelação, mas também de vida e de fonte de vida. ${ }^{41}$

\section{Considerações finais}

Diante do exposto, conclui-se que a teologia joanina apresenta um dualismo vertical: mundo de cima e mundo de baixo. As imagens têm por objetivo apontar que, o mundo de cima é o mundo de Deus, em contraste com o mundo de baixo. $O$ autor associa aspectos negativos a esse mundo de baixo (carne, trevas, noite, diabo), já no que tange ao mundo de cima, o autor apresenta aspectos positivos (Espírito, luz, dia, Deus). Para fazer parte do Reino de Deus é necessário, conforme apresentado na teologia joanina na perícope em tela, nascer de novo.

Além disso, é necessário cuidado na leitura das imagens dualistas no Evangelho de João. Há momentos em que a leitura deve ser feita de modo literal, há momentos nos quais se deve ler metaforicamente e há, ainda, uma terceira possibilidade: literal e ao mesmo tempo com um sentido velado, isto é, metafórico. Na pesquisa, constatamos que a "noite" em João 3.1-6 deve ser lida dentro dessa terceira possiblidade. Assim, ao mesmo tempo em que Nicodemos esteve com Jesus à noite, ele também vivia a sua própria noite; em sentido joanino, estava em trevas.

A partir da proposta de interpretação supracitada, pode-se constatar que o novo nascimento, da perspectiva da teologia joanina, constitui-se o fator fundamental para a garantia da entrada no Reino de Deus. Esse nascimento do alto é promovido pela fonte água-espírito, os quais proporcionam aos regenerados uma nova vida, promovida pelo Espírito Santo.

O texto apresenta Nicodemos, um homem letrado na Torá, membro do Sinédrio, alguém de amplo conhecimento que, no entanto, diante do diálogo com Jesus, mostra-se duvidoso quanto ao novo nascimento. Parece-nos que, embora na perícope seja Nicodemos o duvidoso, o objetivo é mostrar que assim como ele, uma figura de destaque, outros fariseus estão na mesma condição. Ademais, enquanto fariseu, cria que pela prática da Lei teria acesso garantido ao Reino escatológico do Messias. Logo, a necessidade de nascer de novo/do alto gerou em Nicodemos estranheza, fato que propiciou, dentro da estrutura narrativa, Jesus apresentar sua explicação, demonstrando que

39 LADD, George Eldon. Teologia do Novo Testamento. São Paulo: Hagnos, 2003. p. 420.

40 CARSON, 2007, p. 198-199.

41 MOLTMANN, Jürgen. O Espírito da vida: uma pneumatologia integral. Petrópolis: Vozes, 1999. p. 19.

Protestantismo em Revista | São Leopoldo | v. 45, n. 02 | p. 167-176| Jul./dez. 2019

Disponível em: <http://periodicos.est.edu.br/index.php/nepp> 
os nascidos de novo vivem de uma maneira que os que não são renascidos não conseguem compreender.

Por fim, a conexão através do dualismo joanino carne-espírito ou mundo de baixo e mundo de cima é intensa, uma vez que a perícope apreciada nos permite entender que o verbo de Deus, que é Espírito, foi gerado em carne - enfatizando a encarnação do verbo (Jo 1.1) - para que o ser humano, que é nascido da carne - portanto guiado pela carne, pois para efeito da teologia joanina a carne em si mesma não é má, mas foi afetada pelo pecado - fosse gerado pelo Espírito. Assim, mediante o novo nascimento, o autor destaca que a participação no Reino de Deus não se dá pelas obras da Lei, mas pela ação do Espírito no mundo.

\section{Referências}

BIBLIA. Bíblia de Jerusalém. São Paulo, Paulus, 2002.

BLOMBERG, Craig L. Jesus e os evangelhos: uma introdução ao estudo dos 4 evangelhos. São Paulo, Vida Nova, 2009.

BROWN, R. E. A Comunidade do Discípulo Amado. São Paulo: Paulus, 1999.

BRUCE, F. F. João: introdução e comentário. São Paulo: Vida Nova, 1987.

CARSON, D. A. Comentário de João. São Paulo: Shedd Publicações, 2001.

HALE, B. D. Introdução ao Estudo do Novo Testamento. São Paulo: Hagnos, 2001.

HENDRIKSEN, Willian. O Evangelho de João. São Paulo: Cultura Cristã, 2004.

KEENER, Craig S. O Espírito nos evangelhos e em Atos: pureza e poder divino. São Paulo: Vida Nova, 2018.

KÖSTENBERGER, Andreas J. SWAIN, Scott R. Pai, Filho e Espírito: a trindade e o evangelho de João. São Paulo: Vida Nova, 2014.

KÜMMEL, Werner Georg. Introdução ao Novo Testamento. 17 ed. São Paulo: Paulus, 1982.

KÜMMEL. Síntese Teológica do Novo Testamento. São Paulo: Teológica, 2003.

LADD, George Eldon. Teologia do Novo Testamento. São Paulo: Hagnos, 2003.

LOUW, Johannes. NIDA, Eugene. Léxico Grego-Português do Novo Testamento baseado em domínios semânticos. Trad: Vilson Scholz. Barueri: Sociedade Bíblica do Brasil, 2013.

MARSHALL, I. Howard. Teologia do Novo Testamento: diversos testemunhos, um só evangelho. São Paulo: Vida Nova, 2007.

MICANTO, Ramiro. A macroestrutura narrativa do quarto evangelho. In: Revista Teocomunicação. Porto Alegre, v.37, n. 155, 2007, p. 49-59.

MOLTMANN, Jürgen. O Espírito da vida: uma pneumatologia integral. Petrópolis: Vozes, 1999.

PERKINS, Pheme. Evangelho segundo João. In BROWN, Raymond E. FITZMYER, Joseph A. MURPHY, Roland E. Novo comentário Bíblico São Jerônimo: Novo Testamento e artigos sistemáticos. Santo André: Academia Cristã; São Paulo: Paulus, 2011. 